\title{
HIV/AIDS and Poverty: Evidence from the Free State Province $^{1}$
}

\section{F le R Booysen}

Department of Economics \& Centre for Health Systems Research \& Development, University of the Free State

\section{ABSTRACT}

Poverty is likely to deepen as the AIDS epidemic takes its course, with households being caught up in a vicious cycle of poverty and HIV/AIDS. This paper shows that affected households are poorer than non-affected households, regardless of whether income is measured at the household, per capita or adult equivalent level and regardless of the poverty line or poverty measure employed in measuring poverty. The incidence, depth and severity of poverty are worse amongst affected households, particularly amongst affected households that have experienced illness or death. The evidence underscores the importance in the longer term of economic policies focused on job creation and education in mitigating the impact of HIV/AIDS, with poverty alleviation through an enhanced social safety net being important in the short to medium-term.

JEL I0-*

\section{INTRODUCTION}

The HIV/AIDS epidemic poses a severe threat to the economies of developing countries, and those on the African continent in particular. South Africa, which is being affected fundamentally by the epidemic, is no exception. By the end of 1997, an estimated 2.8 million adults in South Africa were living with HIV/AIDS. By 2001, this figure had increased to 4.7 million. The estimated prevalence of HIV/AIDS among the country's adult population (20.1 per cent) is amongst the highest in the world (ILO, 2000; UNAIDS, 2002). According to the Metropolitan-Doyle model, the annual number of AIDS deaths is estimated to increase from 120000 to between 545 and 635 thousand between 2000 and 2010. The number of children younger than fifteen years orphaned by AIDS has been estimated to be 800000 by 2005, rising to more than 1.95 million by 2010 (Abt Associates, 2000: 8-11). 
These infected individuals and affected children all belong to individual households (meaning that an even larger number of people are affected by the epidemic in some way) and their deaths will have a significant impact on their families. Poverty, moreover, is likely to deepen as the epidemic takes its course. The socio-economic impact of HIV/AIDS combine to create a vicious cycle of poverty and HIV/AIDS in which affected households are caught up. As adult members of the household become ill and are forced to give up their jobs, household income will fall. To cope with the change in income and the need to spend more on health care, children are often taken from school to assist in caring for the sick or to work so as to contribute to household income. Because expenditure on food comes under pressures, malnutrition often results, while access to other basic needs such as health care, housing and sanitation also comes under threat. Consequently, the opportunities for children for their physical and mental development are impaired. This acts to further reduce the resistance of household members and children (particularly those that may also be infected) to opportunistic infections, given lower levels of immunity and knowledge, which in turn leads to increased mortality (World Bank, 1998; Bonnel, 2000: 5-6; Wekesa, 2000). Households headed by AIDS widows are also particularly vulnerable, because women have limited economic opportunities and traditional norms and customs may see them severed from their extended family and denied access to an inheritance (UNDP, 1998). Worrying, more, is that firms are increasingly using contract labor rather than appointing employees on a permanent basis, which increasingly shifts the burden of HIV/AIDS onto households and government (Rosen \& Simon, 2002). This also means that HIV/AIDS-affected households (and in particular infected persons) may find it increasingly difficult to find employment and remain in employment, which is crucial for ensuring some kind of economic security at the household level. In many third world situations, therefore, HIV/AIDS exposes already vulnerable, resource-poor households to further shocks.

These are all ways in which HIV/AIDS can cause poverty to increase. Whiteside (2001/02) describes the above linkages between HIV/AIDS and poverty in considerably more detail, but then goes on to point out that poverty can also result in increased vulnerability to HIV/AIDS, which in turn can aid the spread of the disease. Poverty, apart from being associated with poor nutrition and a breakdown of immune systems, also stand to increase the vulnerability of people to HIV/AIDS by resulting amongst others in unsafe sexual practices as a result of lack of knowledge and lack of access to means of protection, due to women's inability to negotiate about condom use with sexual partners as a result of entrenched gender roles and power relations, and because of violence and coercion (Whiteside, 2001/02). In fact, both Desmond (2001) and Whiteside (2002) emphasize how complex the relationship between poverty and HIV/AIDS actually is and how many facets it has, e.g. how labor migration 
induced by rural poverty can contribute to the spread of the disease and how poor, single mothers may be forced to become occasional sex workers in order to survive (Desmond, 2001: 56; Poku, 2001: 195). Gillies et al. (1996) and Nyamathi et al. (1996), moreover, highlight the importance of homelessness, urban/rural migration patterns, migrant labor practices and the breakdown of social support networks in communities with limited access to social service delivery and in developing countries in increasing the vulnerability of poor people to HIV/AIDS. This paper deals primarily with the question of the extent to which HIV/AIDS (via increased morbidity and mortality, as well as other HIV/AIDS-related impacts) can cause poverty to increase.

\section{DATA AND METHOD}

The impact of HIV/AIDS on households was assessed by means of a cohort study of households affected by the disease, and compared with a control group of households not currently affected by the disease. The survey was conducted in two local communities in the Free State province, one urban (Welkom) and one rural (Qwaqwa), in which the HIV/AIDS epidemic is particularly rife. Affected households were sampled purposively via NGOs and other organizations involved in AIDS counseling and care and include at least one person known to be HIV-positive or known to have died from AIDS in the past six months. Informed consent was obtained from the infected individual(s) or their caregivers (in the case of minors). Non-affected households represent households living in close proximity to these affected households, but which did not at the time of the first interview include persons suffering from chronic HIV/AIDS-related diseases such as tuberculosis or pneumonia. Affected and non-affected households are compared, whilst the analysis also distinguishes between households that have experienced illness or death and those that have not experienced illness or death. Due to the nature of the disease (i.e. HIV only develops into AIDS over a relatively long incubation period), the sample includes a number of affected households that as yet has not experienced any illness or death.

Households were defined in terms of the standard definition employed by Statistics South Africa in the October Household Survey, i.e. "a person or a group of persons who live together at least four nights a week at the same address, eat together and share resources". A survey on the quality of life and household economics was conducted. Interviews were conducted with one key respondent only, namely the "person responsible for the daily organization of the household, including household finances". The results reported in this paper are based an analysis of the data for the 387 households that were interviewed in 
both wave I and in II of this study. The two waves of data collection were respectively completed in May/June and November/December 2001.

Although the sample population in certain instances closely reflects the socioeconomic profile of the national population (e.g. male/female distribution), it in most cases differs distinctly from the general South African population (Booysen et al., 2002). The profile of the sample of households included in this study can largely be attributed to the sampling design. Given that affected households were sampled from networks and/or organizations involved in counseling, home-based care and public health care and mainly in poorer communities, the sample does not include affected households that mainly utilize private health care services. Moreover, the study was conducted in one specific province (Free State) and in two selected sites only. However, the fact that South Africa's poor, predominantly African population face relatively high HIV prevalence rates and are particularly vulnerable to the epidemic and therefore dependent on support from the public service sphere, means that the findings and policy recommendations put forward in this paper are especially relevant to informing government's responses to HIV/AIDS.

\section{DISCUSSION}

\subsection{Measurement of standard of living}

Poverty (or standard of living) is measured at the household rather than the individual level, given that the focus here is on the household impact of HIV/AIDS. Poverty is here interpreted in terms of the command over commodities that resources afford people via income and consumption (Lipton \& Ravallion, 1995: 2553-67). The concern, therefore, is with 'poverty proper' (i.e. resource adequacy) and not with the physiological, sociological or political dimensions of poverty (Kgarimetsa, 1992: 8; Woolard \& Leibbrandt, 1999: 3).

Generally, a single monetary indicator, such as income or consumption, is employed in assessing the extent of poverty and inequality (Ravallion, 1996: 1328-34). Income is argued to reflect consumption opportunities and is therefore a popular measure of poverty (Hagenaars, 1991: 135-46). During the survey, data were collected from one informant regarding the employment income, nonemployment income and receipts of remittances for the members of the particular household. An estimate of total monthly household income was derived from these figures by adding up the various component items. Consumption represents an alternative resource base for measuring poverty and inequality (Lipton, 1997: 1003). During the survey, fieldworkers collected expenditure-related data from the household member in charge of household 
finances in each of these households. This include estimates of household expenditure on specific items such as food, education, health care, transport, monthly repayments of debt, and clothing, as well as remittances made to persons not living with the household. As in the case of income, an estimate of total monthly household expenditure was calculated by adding these items together.

Income, however, in a certain sense represents an inadequate measure of poverty. So, for example, it is generally assumed that household income is employed in a manner that benefits the whole family. Yet, this may not necessarily be the case, given inequalities and inequities in the intra-household allocation of resources (Woolley \& Marshall, 1994: 422-9). Furthermore, levels of income and consumption often differ as a result of consumption smoothing. Consumption also represents a better proxy of current living standards and longterm average well being than income for other reasons. Consumption bridges the observed disparity between income and expenditure levels. Expenditure also reveals information about both past and future incomes, because it includes consumption financed from savings (Lipton \& Ravallion, 1995: 2573).

The income-based estimates of household welfare in the case of this study exceed the expenditure-based estimates. Normally, one would expect the opposite, with expenditure-based estimates exceeding income-based estimates of household welfare. This may be because the one informant that was interviewed (i.e. the person in charge of household finances) generally has a better idea of the employment status and average earnings of other members of the household (in fact, the person during the interview often verified this information with other household members). This person, moreover, is unlikely to be knowledgeable about the manner in which each member of the household spends their income. In fact, individuals and/or households have been found to rarely record expenditure data in detail (Woolard \& Leibbrandt, 1999: 23-24). Expenditure, therefore, in this case most likely reflects only that amount of resources of household members that is spent on communal household needs.

The literature, moreover, suggests that HIV/AIDS can impact on household income and expenditure in different ways. On the one hand, the changes in the supply of household labor caused by AIDS morbidity and mortality are likely to be accompanied by a drop in household income. On the other hand, household expenditure may increase initially following illness or death, given that households need to spend more on medical care and funerals. In the Kagera study, for example, the total level of expenditure was 25 percent higher in households suffering an adult death than in household where no adult death occurred (Lundberg \& Over, 2000). In the case of rural Thailand, though, per capita expenditure in households affected by an adult death on average dropped 
by 43.5 percent (Kongsin et al., 2000, as quoted in Parker et al., 2000: 44). As a result, the income-based estimates are likely to represent a more reliable measure of the standard of living of these households and are likely to be a better proxy of the impact of HIV/AIDS on household welfare, which means that this paper employs household income as proxy of standard of living rather than household expenditure.

Households with the same level of income do not necessarily enjoy the same level of welfare. The larger the household, the lower the level of welfare at similar levels of household income. Measures of equivalent income are employed to allow for these differences in standard of living related to household characteristics (Lipton \& Ravallion, 1995: 2574; Burkhauser et al., 1997: 154-61). Estimates of household income were here adjusted for differences in household size by dividing total monthly income by ${ }^{\alpha}$, where $n$ represents the number of household members and $\alpha$ an adjustment for household economies of scale (Filmer \& Pritchett, 1998: 13). According to Lanjouw \& Ravallion (1995) and Drèze \& Sen (1997), a $\alpha$ coefficient of 0.6 represents an adequately robust and reliable adjustment for household economies of scale.

\subsection{Comparisons of levels of household income}

Table 1 report on the average adult equivalent per capita household income of affected and non-affected households. A distinction is also made between affected households that have experienced illness (i.e. a member of the household has been chronically ill in the thirty days preceding the interview) or death (i.e. a member of the household has died in the six months preceding the first interview or in the time elapsed following the first interview) and those that has not been affected by morbidity or mortality.

\section{Table 1 Average monthly adult equivalent per capita income for} affected and non-affected households (rand)

\begin{tabular}{|c|c|c|c|c|c|c|c|}
\hline & \begin{tabular}{|c|} 
Total \\
sample
\end{tabular} & $\begin{array}{c}\text { Affected } \\
\text { house- } \\
\text { holds }\end{array}$ & $\begin{array}{c}\text { Non- } \\
\text { affected } \\
\text { house- } \\
\text { holds }\end{array}$ & $\begin{array}{c}\text { Affected } \\
\text { households } \\
\text { suffering } \\
\text { illness/death }\end{array}$ & \begin{tabular}{|c|} 
Affected \\
households \\
suffering \\
no illness/ \\
death
\end{tabular} & $\begin{array}{c}\text { Non- } \\
\text { affected } \\
\text { households } \\
\text { suffering } \\
\text { illness/ } \\
\text { death }\end{array}$ & $\begin{array}{c}\text { Non- } \\
\text { affected } \\
\text { households } \\
\text { suffering } \\
\text { no illness/ } \\
\text { death } \\
\end{array}$ \\
\hline Wave I & 716 & 510 & 916 & 449 & 799 & 695 & 972 \\
\hline Sample (n) & 375 & 185 & 190 & 153 & 32 & 38 & 152 \\
\hline Wave II & 624 & 471 & 773 & 411 & 767 & 660 & 799 \\
\hline Sample (n) & 373 & 184 & 189 & 120 & 64 & 32 & 157 \\
\hline
\end{tabular}


Note: The reported sample sizes reflect those of the total 387 households interviewed in both waves that actually reported an income.

The loss of labor supply brought about by AIDS will cause household income to decline (Topouzis, 2000). Consequently, affected households (and in particular ones affected by morbidity or mortality) should be poorer than non-affected households. This fact is born out in the results presented in Table 1 and Figure 1. Adult equivalent per capita income in affected households represents only between 50 per cent and 60 per cent of the levels of income in mn-affected households (Table 1), as is the case with total household income and per capita household income (Figure 1). The comparison of the two groups of affected households (these households all include someone known to be HIV/AIDS positive) presents even clearer evidence of the likely effect of HIV/AIDS on household welfare. The adult equivalent per capita income of affected households that has experienced illness or death is substantially lower than is the case in affected households that has not suffered illness or death (Table 1). This is also the case where non-affected households that have experienced illness or death are compared with ones that have not, thus illustrating how illness and death in general impacts on household welfare even where it is not necessarily related to HIV/AIDS (i.e. testing was not conducted and non-affected households were only screened for the presence of certain chronic illnesses in wave I).

Also evident from Table 1 is that income has declined between the two waves, both in the case of affected and non-affected households as well as in the total sample. These differences in some cases are relatively small, but may be pointing towards a general decline in levels of income. However, it is felt that more panels are required to determine real trends in household income and therefore to substantiate the findings reported here, particularly insofar as income is measured off a relatively low base (i.e. the study population generally is quite poor), which makes it difficult to distinguish between real trends and small differences in income, particularly in the context of problems of measurement error. 


\section{Figure 1 Average household income in wave I and II}

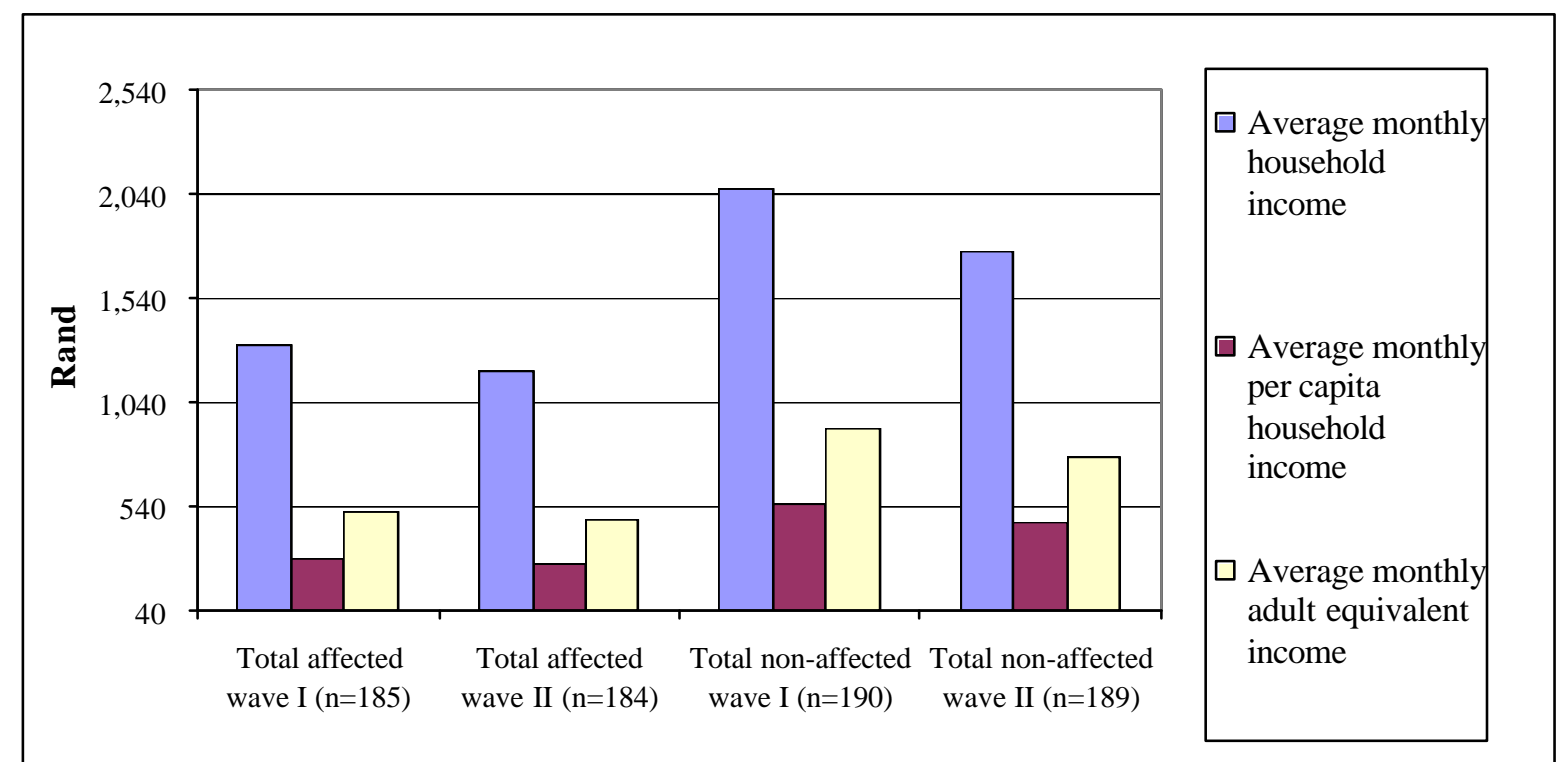

Note: The reported sample sizes reflect those of the total 387 households interviewed in both waves that actually reported an income

The available evidence from other household impact studies supports the above findings, i.e. that households affected by HIV/AIDS generally are poorer than non-affected households. Only one study reports on the impact of AIDS morbidity on household income. Households living in rural Chanyanya in the Kafue district in Zambia that were affected by chronic illness had an annual income 46 per cent lower than households in the same area that were not affected by chronic illness (Mutangadura \& Webb, 1999, as quoted in Topouzis, 2000: 18). A number of studies have reported on the effect of AIDS mortality on household income. So, for example, households in Zambia that have suffered a paternal death have experienced a drop in monthly disposable income in excess of 80 percent (Nampanya-Serpell, 2000). Households in rural Thailand affected by an adult death saw household income drop by 70.7 per cent, while total per capita income dropped by 68.4 percent (Kongsin et al., 2000, as quoted in Parker et al., 2000: 44). A study in the Ivory Coast, which fails to indicate whether the focus in on AIDS morbidity or mortality, reported that the household income of affected families was found to be half that of total average household income (Bechu, 1998, as quoted in Desmond et al., 2000: 5).

\subsection{Comparisons of incidence, depth and severity of poverty}

Apart from describing differences between affected and non-affected households in terms of general levels of welfare (or household income in this case), one would also want to determine how poverty differs between affected and nonaffected households. To estimate poverty one requires a poverty line, i.e. a level 
of income below which people are considered poor. Poverty lines provide a yardstick with which to compare the circumstances of individual households. Aggregate measures of poverty cannot be estimated without a poverty line. Armed with the estimate of household income and the poverty line estimate, one can aggregate this information into a variety of descriptive measures of poverty and inequality (Grootaert, 1983: 3-10). The following specific measures of poverty and inequality are employed in this analysis ${ }^{2}$.

The Gini coefficient $(\mathrm{G})$ represents the average ratio between the proportion of total income actually earned by a specific household and the proportion of income the household would have earned had income been distributed equally. $\mathrm{G}=0$ denotes total equality and $\mathrm{G}=1$ total inequality (Paukert, 1973). Because inequality is an important determinant of poverty, an analysis of the extent of income inequality can provide an important pointer to determining whether poverty is more severe amongst affected than non-affected households. If inequality is more pronounced amongst affected households, one would expect that more affected households fall below the poverty line. This in turn will mean that poverty is more prevalent amongst affected households, which can be determined by comparing the estimates of the following poverty indices across affected and non-affected households.

The headcount poverty index $(\mathrm{H})$ is a measure of the prevalence or incidence of poverty, i.e. the percentage of the population with a level of income below the poverty line $(\mathrm{z})$. The poverty gap index (PG) is a measure of the intensity or depth of poverty that allows for how far the poor fall below the poverty line. The squared poverty gap index (SPG) represents a measure of the severity of poverty that allows for the extent of inequality amongst the poor. The SPG attaches more weight to those gains furthest from the poverty line. The headcount, poverty gap and squared poverty gap indices are special cases of the Foster-Greer-Thorbecke (FGT) class of poverty measures. $\mathrm{P}_{\alpha}=1 / \mathrm{n} \Sigma\left[\mathrm{z}-\mathrm{y}_{\mathrm{i}} / \mathrm{z}\right]^{\alpha}$, where $\mathrm{z}$ represents the poverty line and $y_{i}$ the actual income or consumption level of each person or household. The three FGT measures each focus on a different conventional poverty measure. $\mathrm{P}_{0}, \mathrm{P}_{1}$ and $\mathrm{P}_{2}$ respectively are derivatives of the headcount $(\mathrm{H})$, poverty gap (PG) and squared poverty gap (SPG) indices (Greer \& Thorbecke, 1986). As explained above, these poverty measures become more sensitive to the well-being of the poorest person as the value of $\alpha$ increases (Woolard \& Leibbrandt, 1999: 28). 
Table 2 Estimates of the headcount poverty index (h), poverty gap measure (pg), squared poverty gap index (spg) and ginicoefficient for affected and non-affected households

\begin{tabular}{|c|c|c|c|c|c|c|c|}
\hline & $\begin{array}{l}\text { Total } \\
\text { sam- } \\
\text { ple }\end{array}$ & $\begin{array}{l}\text { Affected } \\
\text { house- } \\
\text { holds }\end{array}$ & $\begin{array}{l}\text { Non- } \\
\text { affected } \\
\text { house- } \\
\text { holds }\end{array}$ & \begin{tabular}{|l} 
Affected \\
house-holds \\
suffering \\
illness/- \\
death
\end{tabular} & \begin{tabular}{|l|} 
Affected \\
house-holds \\
suffering \\
no illness/- \\
death
\end{tabular} & $\begin{array}{l}\text { Non- } \\
\text { affected } \\
\text { house-holds } \\
\text { suffering } \\
\text {-illness/- } \\
\text { death }\end{array}$ & $\begin{array}{l}\text { Non- } \\
\text { affected } \\
\text { households } \\
\text { suffering } \\
\text { no illness/- } \\
\text { death }\end{array}$ \\
\hline \multicolumn{8}{|c|}{ A. Wave I } \\
\hline $\mathrm{H}$ & 36.99 & 44.74 & 29.55 & 48.85 & 26.11 & 34.44 & 27.98 \\
\hline $\mathrm{PG}$ & 16.32 & 19.75 & 13.14 & 20.93 & 15.71 & 15.56 & 12.44 \\
\hline SPG & 9.20 & 11.21 & 7.55 & 11.44 & 13.27 & 9.16 & 7.15 \\
\hline Gini & 59.90 & 56.50 & 59.60 & 54.44 & 60.08 & 57.91 & 59.35 \\
\hline $\begin{array}{l}\text { Sample } \\
\text { (n) }\end{array}$ & 375 & 185 & 190 & 153 & 132 & 38 & 152 \\
\hline \multicolumn{8}{|c|}{ B. Wave II } \\
\hline $\mathrm{H}$ & 51.03 & 57.27 & 44.37 & 55.63 & 41.72 & 46.38 & 43.24 \\
\hline PG & 24.24 & 27.22 & 20.67 & 24.34 & 20.13 & 20.02 & 20.34 \\
\hline SPG & 14.55 & 16.39 & 12.28 & 13.82 & 12.59 & 11.08 & 12.23 \\
\hline Gini & 69.85 & 65.33 & 71.36 & 58.11 & 70.25 & 68.25 & 71.56 \\
\hline $\begin{array}{l}\text { Sample } \\
(\mathrm{n})\end{array}$ & 373 & 184 & 189 & 120 & 64 & 32 & 157 \\
\hline
\end{tabular}

Note: The reported sample sizes reflect those of the total 387 households interviewed in both waves that actually reported an income

The Gini coefficients and poverty indices calculated for each of the groups of affected and non-affected households are reported in Table 2. The results are here reported only for the poverty line of R250 adult equivalent per capita income, which was employed in the most recent poverty estimates published by Statistics South Africa (2000: 11), albeit not in adult equivalent form. Evident from the results in Table 2 is that the degree of inequality is slightly higher amongst non-affected households than amongst affected households. These differences in the extent of income inequality are even more pronounced in the case of the comparison between the two groups of affected households, i.e. those having experienced illness or death and those not having experienced illness or death, while it also holds for the comparison across the two groups of nonaffected households. This may be the result of households experiencing illness or death being more likely to have a lower income, which translates into relatively lower levels of income and relatively less variation in income (at least across the higher ranges), which in turn means that the extent of income 
inequality is likely to be less pronounced. In the case of non-affected households, variation in household income is more pronounced, translating into higher levels of income inequality. Interesting, furthermore, is that inequality has increased between wave I and wave II of the study, this being the case in all subgroups of affected and non-affected households, as well as in the total sample population. As explained elsewhere, more panels are required to determine real trends in income and therefore in the extent of income inequality.

According to the results presented in Table 2, the incidence, depth and severity of poverty are worse amongst affected households than amongst non-affected households. This is also the case when comparing the estimates of the incidence and depth of poverty across affected and non-affected household that have experienced illness or death as opposed to affected and non-affected households that have as yet not experienced illness or death. According to these estimates, poor, affected households will have to boost their income by nearly twenty (wave I) and twenty-eight per cent (wave II) to reach the poverty line. Nonaffected households in turn only have to boost their income by approximately thirteen (wave I) and twenty-one per cent (wave II) to reach the same poverty line. Thus, poverty does appear to be significantly worse amongst affected households. The comparison of poverty estimates across the two rounds of interviews also seems to suggest that the incidence, depth and severity of poverty are on the increase, albeit the case for both affected and non-affected households. In fact, poverty is relatively pronounced in both these communities, with a relatively high proportion of both affected and non-affected households being classified as poor (e.g. the headcount index respectively amounts to 37 and 51 percent in wave I and wave II). According to Statistics South Africa (2000), the headcount poverty ratio in the magisterial districts of Welkom and Witsieshoek (which lies within the boundaries of the former Qwaqwa) respectively are 0.34 (this is likely to be much higher in the African communities in which this survey was conducted) and 0.69 , while the estimate of average monthly household expenditure respectively amounts to R2364 (again likely to be much lower for the residents of the African and Colored townships where the survey was conducted) and R807. Again, caution is required insofar as data from more panels are required to validate such claim and to establish trends in poverty. One may therefore tentatively conclude that poverty indeed is worse amongst affected than amongst non-affected households.

\subsection{Robustness of poverty comparisons}

In order to further substantiate such argument, one needs to perform a number of poverty comparisons. The main purpose with a poverty comparison is to determine whether the results of such comparison are robust and consistent. The 
conclusion drawn from a poverty comparison, i.e. whether affected households are poorer than non-affected households or not, should not be dependent on the choice of a particular standard of living indicator, poverty line, or poverty measure (Ravallion \& Bidani, 1994: 76; Ravallion, 1994b: 44-51). The robustness of a poverty comparison is determined by comparing the headcount, poverty gap and squared poverty gap index across a critical range of poverty lines. Arbitrariness is practically unavoidable in setting poverty lines, primarily because of the multitude of methods that are employed for this purpose (Kgarimetsa, 1992: 9; Alcock, 1993: 60-62; Johnson, 1996: 110-12). Hence, the standard practice has become one of testing the robustness of poverty lines by simultaneously employing more than one such estimate in poverty analysis. Ravallion (1994b: 43) refers to this as the use of dual poverty lines. Results are compared across poverty line estimates based on different methodologies and/or alternative assumptions made using similar methods (Lipton \& Ravallion, 1995: 2577; Lipton, 1997: 1003).

A similar approach is followed here. The range of poverty lines used for this purpose varies from R100 to R600 in adult equivalent per capita terms, which covers all the currently available poverty line estimates for South Africa, even when allowing for the effect of inflation (Klasen, 1997: 56; Woolard \& Leibbrandt, 1999: 14; Booysen, 2001: 680). Partial poverty orderings or poverty value curves are used for the purposes of presenting the results (Ravallion, 1994b: 1-3; Woolard \& Leibbrandt, 1999: 12). To obtain these curves, estimates of the headcount, poverty gap and squared poverty gap indices for the subgroups of households are plotted for the critical range of poverty lines. The values of the poverty measure are plotted on the vertical axis and the cumulative values of the poverty line are plotted on the horizontal axis. A comparison is robust and consistent if the poverty value curve for one subgroup dominates and/or matches that of another subgroup across the entire range of poverty line estimates. This means that one subgroup is poorer than another subgroup regardless of the poverty line used for comparative purposes. Only the poverty incidence dominance curves for each of the four main clusters of households are reported here (figures 2 to 5). According to Ravallion \& Sen (1996: 776), the conditions for dominance are likely to hold for the poverty gap and squared poverty gap measures if it holds for the headcount index.

Evident from figures 2 and 3, is that levels of poverty are generally higher amongst affected households, regardless of the choice of poverty line. The poverty incidence curve for affected households dominates that for non-affected households across the entire range of poverty lines. Poverty, therefore, does seem to be worse amongst affected households. 
Figure 2: Incidence of poverty in affected and non-affected households (wave I)

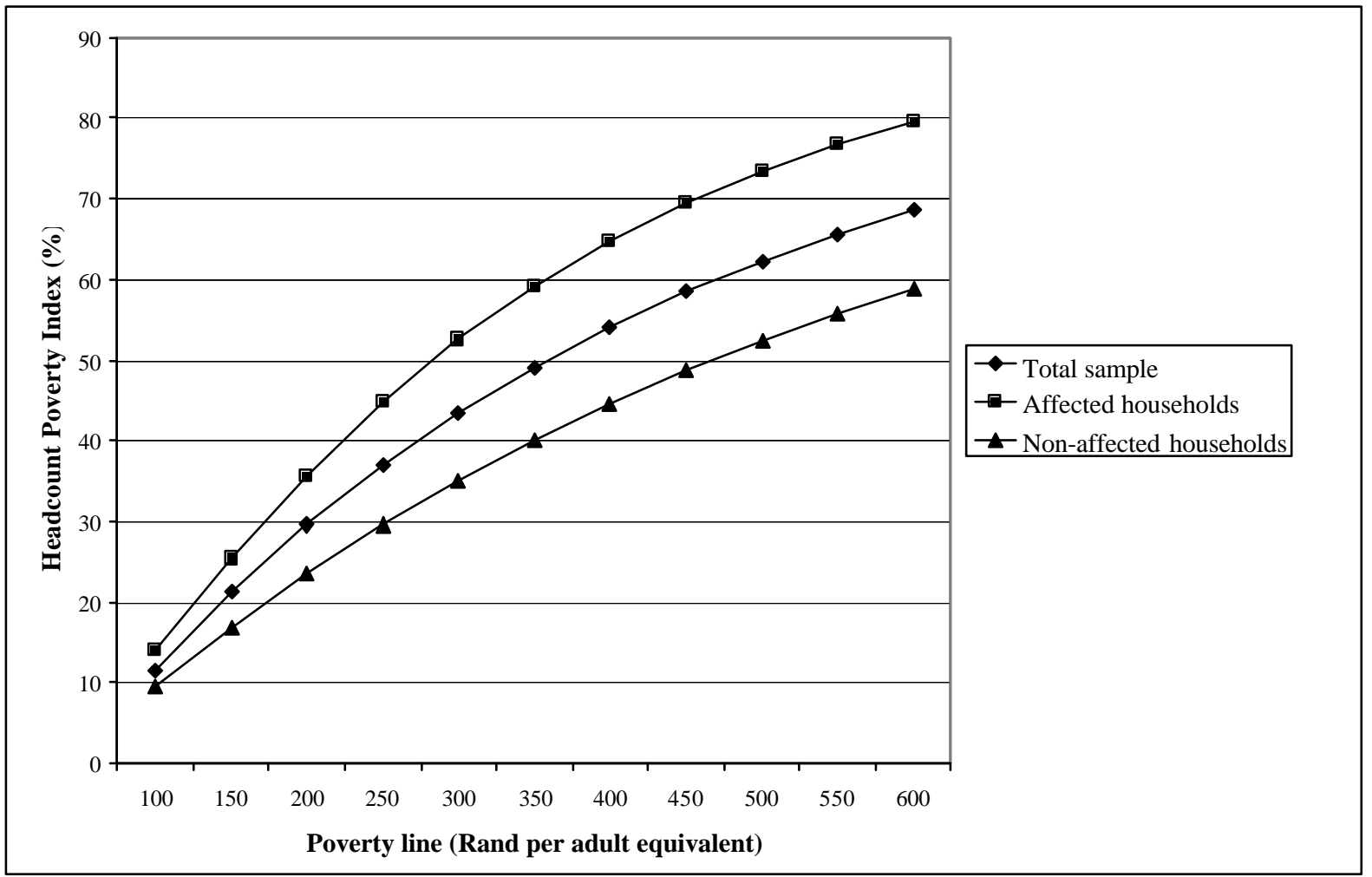

Figure 3: Incidence of poverty in affected and non-affected households (wave II)

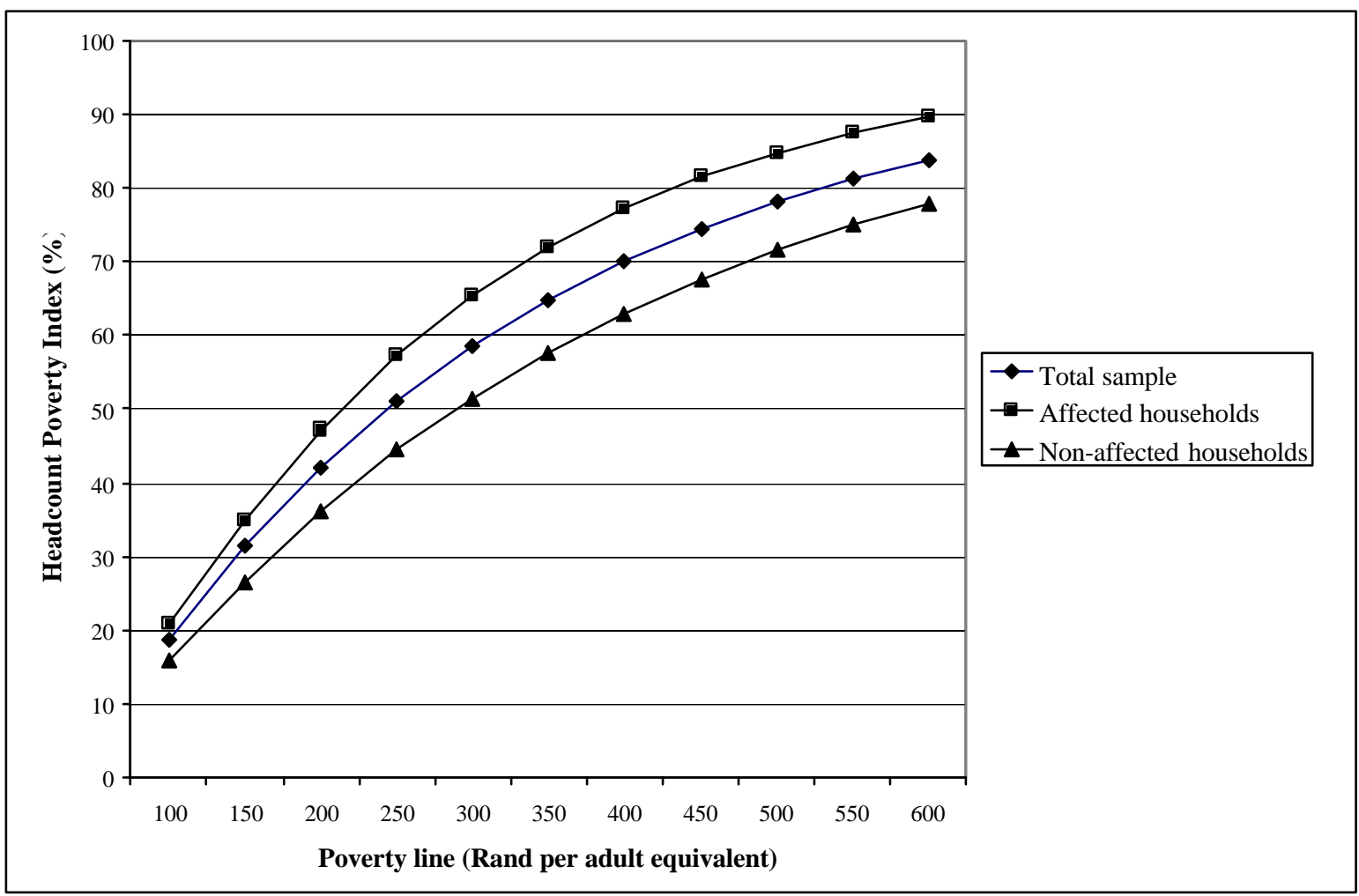


The fact that the socio-economic impact of AIDS is indeed worse in poorer households has been confirmed by Nampanya-Serpell (2000), while much of the analysis following from the Kagera household study has argued that household wealth and access to public services are very important in protecting households from the impact of HIV/AIDS. Impact was found to only be significantly worse in households affected by adult deaths compared to ones with no adult deaths when controlling for differences in socio-economic status (Ainsworth et al., 2000; Ainsworth \& Dayton, 2000; Lundberg \& Over, 2000). Another test of the robustness of the findings presented here is the extent to which poverty is consistently worse amongst households that have directly experienced illness and/or death. Figures 4 and 5 represent the poverty incidence curves for affected and non-affected households by incidence of illness and/or death.

\section{Figure 4 Incidence of poverty in affected and non-affected households by incidence of illness and/or death (wave I)}

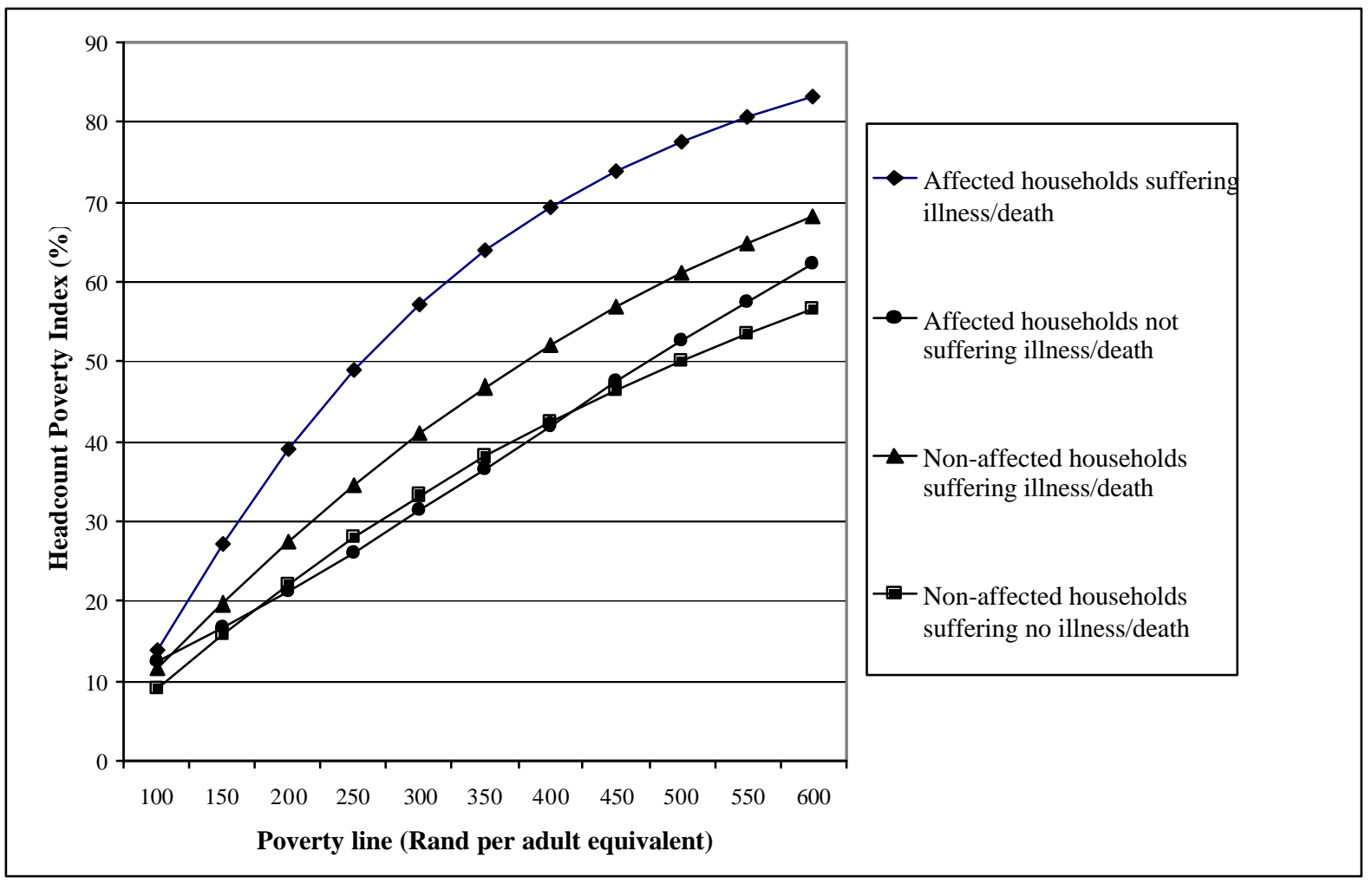

In the case of affected households (i.e. households including at least one person known to be HIV-positive), the incidence of poverty indeed is higher amongst affected households that have experienced illness and/or death than in affected households where this is not the case, regardless of the poverty line employed in quantifying the extent of poverty. Again, therefore, the evidence seems to suggest that HIV/AIDS is likely to result in poverty. In the case of non-affected households, however, the comparison is not consistently robust, with the poverty 
incidence curves crossing at the bottom end of the range of poverty lines in wave II (Figure 5), although being robust in wave I (Figure 4). This could be the result of these households being in a better position than affected households to cope with the resulting loss of supply of labor and household income, e.g. having access to medical aid and having other household members in employment. Yet, it may also be because of the relatively small number of nonaffected households that have experienced illness and/or death $(n<40)$, which makes meaningful comparisons difficult. In addition, the fact that the two waves of data collection were conducted during different times of the year may means that trends in seasonal income could have influenced the results. Here, as is the case with other analysis, data from subsequent follow-ups of households during this longitudinal study will allow one to elucidate these unexplained differences.

\section{Figure 5 Incidence of poverty in affected and non-affected households by incidence of illness and/or death (wave II)}

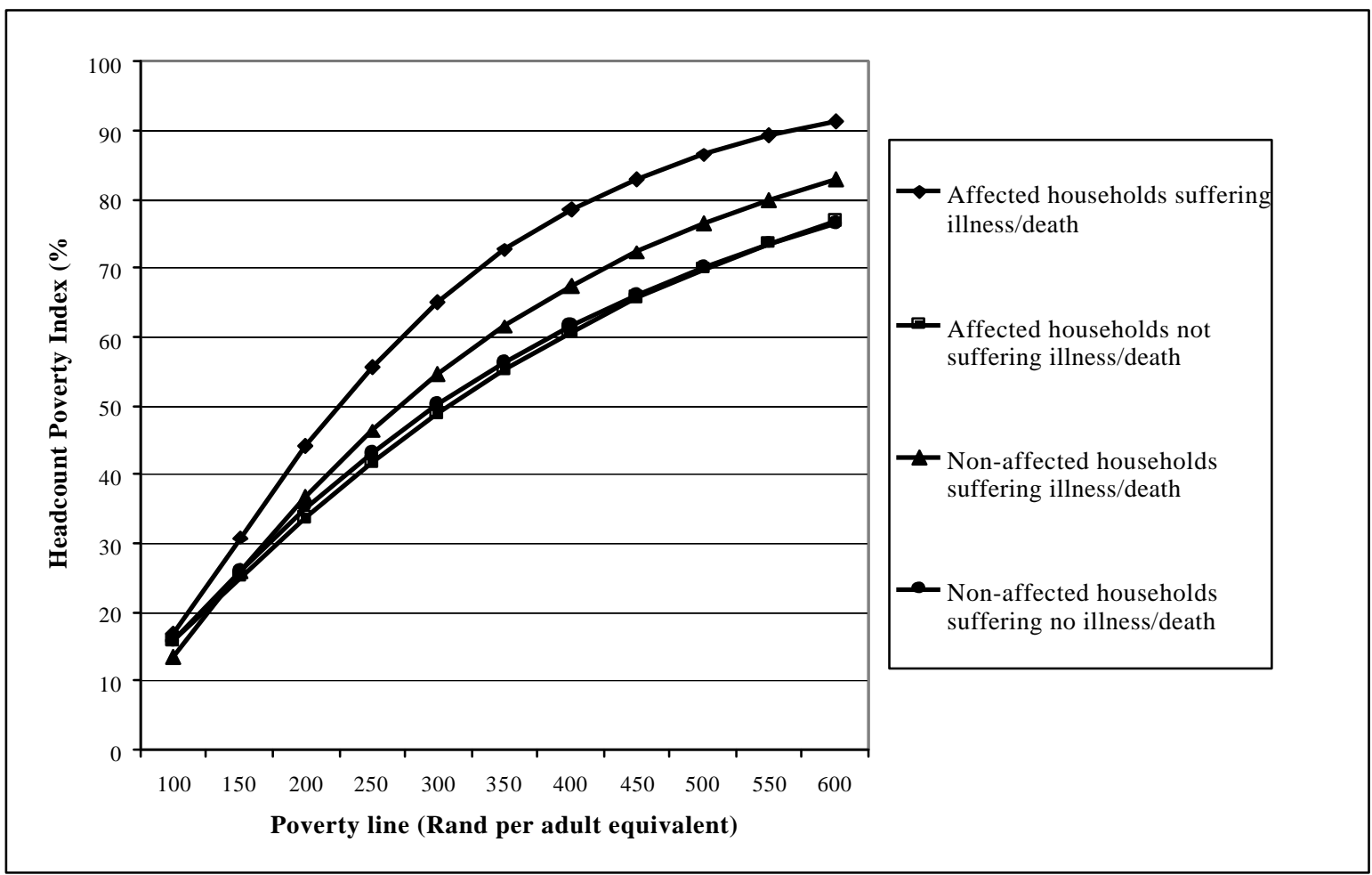

\subsection{Poverty shares}

The above analysis does not take into account how many affected households there are in comparison to non-affected households. Hence, the analysis fails to highlight the extent to which affected and non-affected households share the burden of poverty. Such analysis requires poverty measures that are additively decomposable. Additive decomposability means that overall inequality can be portioned into inequality between subgroups and within subgroups. 
Decomposition across space requires measures of the type $\mathrm{P}_{\alpha}=\mathrm{n}_{\mathrm{A}} \mathrm{P}_{\alpha \mathrm{A}}+\mathrm{n}_{\mathrm{B}} \mathrm{P}_{\alpha \mathrm{B}}$, where $A$ and $B$ represent two subgroups and $n_{A}$ and $n_{B}$ the population shares of the two groups that the poverty estimate $\mathrm{P}_{\alpha}$ for each group is weighted by (Lipton \& Ravallion, 1995: 2580-81). The FGT class of poverty measures is additively decomposable. This feature of the three measures of poverty employed in this analysis makes it possible to determine the share of affected and non-affected households in the poverty burden. Poverty shares were calculated separately for affected and non-affected households, as well as for affected households that have and have not experienced illness and/or death in the recent past. Poverty shares were calculated with reference to the R250 adult equivalent per capita poverty line. The evidence suggests that there is not such a great difference between the share of poverty shouldered by affected and nonaffected households, although affected households bear a larger share of the total burden of poverty, perhaps because of the fact that the two samples are almost equal in size. Affected households have born 53.1 (wave I) and 59.9 percent (wave II) of the burden of poverty, compared to the 46.9 (wave I) and 40.1 percent (wave II) born by non-affected households. However, when the poverty shares are calculated across the sub-sample of affected households only, the results underscore the extent to which affected households that have experienced illness and/or death bear the brunt of poverty compared to affected households not yet affected by illness or death. Households that have experienced illness and/or death respectively have born 71.3 (wave I) and 90 percent (wave II) of the burden of poverty on affected households. As a result, policies aimed at poverty alleviation can be argued to be particularly crucial in sustaining the livelihoods of affected households that have actually experienced illness and/or death.

\section{CONCLUSION}

Affected households are poorer than non-affected households, regardless of whether income is measured at the household or individual level or in adult equivalent terms and regardless of the poverty line and poverty measure employed in measuring poverty. These poverty comparisons are relatively robust, particularly so in the case of the comparison of affected households that have experienced illness or death (and who also bear the major share of the burden of poverty) with affected households that have not experienced illness or death. In other words, the incidence, depth and severity of poverty are relatively worse among affected households and especially among affected households that have suffered illness or death in the recent past. There is also evidence that the extent of income inequality and the incidence, depth and severity of poverty within this relatively small sample of households may be on the increase, albeit 
the case in both the affected and non-affected group of households. The findings therefore suggest that the introduction of a broad-based social security system offering minimal benefits or of specifically targeted welfare programs may in the short and medium term be important in mitigating certain aspects of the impact of the epidemic, e.g. ensuring food security, making sure that children attend school and mitigating the burden of funeral costs, particularly in the case of households that have directly experiences illness or death. In the longer run, however, continued efforts at poverty reduction through improved education opportunities and job creation are likely to remain important. It also means that efforts aimed at ensuring HIV-infected persons equitable access to the labor market will remain crucial in keeping these households from slipping further into poverty. Subsequent follow-up of these households will provide further information on trends in health and socioeconomic status, thus elucidating these complex relationships.

\section{ENDNOTES}

1 This research paper is sponsored by USAID and administered by the Joint Center for Political and Economic Studies Inc. under a subcontract agreement from Nathan Associates Inc. These findings were included in a more extensive research paper presented in Johannesburg at the Annual Conference of the Development Policy Research Unit (DPRU) from 2426 October 2002.

2 The estimates of the measures of poverty and inequality that are presented in these pages were calculated with the aid of the POVCAL program developed by the World Bank. POVCAL is an easy to use and reliable tool for routine poverty assessment work. It uses sound and accurate methods for calculating poverty and inequality measures with only a basic PC and any of the various types of grouped distribution data typically available, often in published form. POVCAL estimates a General Quadratic Lorenz curve and Beta Lorenz curve for each data set and then performs a range of tests to assess the validity of each of the Lorenz curves. The measures of poverty and inequality reported in these pages are based on the General Quadratic Lorenz curves estimated from the tabulated data. The General Quadratic Lorenz curves were invalid only in select cases and then only at the upper extremes of the income distribution, whereas the Beta curves were invalid in most cases. The sum of the squared standard errors over these Lorenz curve were generally extremely small. 


\section{REFERENCES}

1 ABT ASSOCIATES (2000) The Impending Catastrophe: A Resource Book on the Emerging HIV/AIDS Epidemic in South Africa, Johannesburg: Henry J. Kaiser Family Foundation.

2 AINSWORTH, M. \& DAYTON, J. (2000) Is the AIDS Epidemic Having an Impact on the Coping Behaviour and Health Status of the Elderly? Evidence from Northwestern Tanzania, Washington, DC: World Bank.

3 AINSWORTH, M, BEEGLE, K. \& KODA, G. (2000) Impact of Adult Mortality on Primary School Enrolment in Northwestern Tanzania, Washington, DC: World Bank.

4 ALCOCK, P. (1993) Understanding Poverty, Hampshire: Macmillan.

5 BONNEL, R. (2000) "Economic analysis of HIV/AIDS", Paper presented at the African Development Forum, Addis Ababa, 3-7 December.

6 BOOYSEN, F. LE R (2001) "Non-payment of services: A problem of ability to pay", South African Journal of Economics, 69(4): 674-97.

7 BOOYSEN, F. LE R., VAN RENSBURG, H.C.J., BACHMANN, M., ENGELBRECHT, M., STEYN, F. \& MEYER, K. (2002) The Socioeconomic Impact of HIV/AIDS on Households in South Africa: Pilot Study in Welkom and QwaQwa, Free State Province, Report for USAID on Economic Impact of HIV/AIDS in South Africa.

8 BURKHAUSER, R.V., FRICK, J.R. \& SCHWARZE, J. (1997) “A comparison of alternative measures of economic well-being for Germany and the United States, Review of Income and Wealth, 43(2), 153-71.

9 DESMOND, C., MICHAEL, K. \& GOW, J. (2000) The Hidden Battle: HIV/AIDS in the Family and Community, Health Economics \& HIV/AIDS Research Division (HEARD), University of Natal, Durban.

10 DESMOND, D. (2001) "Joint epidemics: Poverty and AIDS in subSaharan Africa", Harvard International Review, Fall: 54-8.

11 DRÈZE, J. \& SRINIVASAN, P.V. (1997) "Widowhood and poverty in rural India: Some inferences from household survey data", Journal of Development Economics, 54: 217-34.

12 FILMER, D. \& PRITCHETT, L. (1998) Estimating Wealth Effects without Expenditure Data - or Tears: An Application to Educational Enrollments in States of India, World Bank Policy Research Working Paper No. 1994. Washington, DC: Development Economics Research Group (DECRG), The World Bank.

13 GILLIES, P., TOLLEY, K. \& WOLSTENHOLME, J. (1996) "Is AIDS a disease of poverty?" AIDS Care, 8(3): 351-63.

14 GREER, J. \& THORBECKE, E (1986) "A methodology for measuring food poverty applied to Kenya", Journal of Development Economics, 24: 59-73. 
15 GROOTAERT, C. (1983) "The conceptual basis of measures of household welfare and their implied survey data requirements", Review of Income and Wealth, 29(1): 1-21.

16 HAGENAARS, A.J.M. (1991) "The definition and measurement of poverty", In Osberg, L. (ed.) Economic Inequality and Poverty: International Perspectives, New York: ME Sharp.

17 INTERNATIONAL LABOUR ORGANISATION (2000) HIV/AIDS: A Threat to Decent Work, Productivity and Development. Geneva: International Labour Office.

18 JANJAROEN, S. (1997) Impact of AIDS on household composition and consumption in Thailand, European Union HIV/AIDS Programme in Developing Countries. Brussels: European Commission.

19 JOHNSON, D. (1996) "Poverty lines and the measurement of poverty", Australian Economic Review, 96(1): 110-26.

20 KGARIMETSA, M. (1992) "The two faces of poverty: Urban and rural", Social Work-Practice, 3: 8-14.

21 KLASEN, S. (1997) "Poverty, inequality and deprivation in South Africa: An analysis of the 1993 Saldru survey", Social Indicators Research, 41: 51-94.

22 LANJOUW, P. \& RAVALLION, M. (1995) "Poverty and household size", Economic Journal, 105: 1415-34.

23 LIPTON, M. \& RAVALLION, M. (1995) "Poverty and policy", In Behrman, J. \& Srinivasan, T.N. (eds.) Handbook of Development Economics (vol. 3) Amsterdam: Elsevier Science.

24 LIPTON, M. (1997) "Editorial: Poverty - Are there holes in the consensus?" World Development, 25(7): 1003-7.

25 LUNDBERG, M. \& OVER, M. (2000) Transfers and Household Welfare in Kagera. Washington, DC: World Bank.

26 NAMPANYA-SERPELL, N. (2000) "Social and economic risk factors for HIV/AIDS-affected families in Zambia", Paper presented at the IAEN AIDS and Economics Symposium, Durban, 7-8 July.

27 NYAMATHI, R.N., FLASKERUD, J., LEAKE, B. \& CHEN, S. (1996) "Impoverished women at risk for AIDS: Social support variables", Journal of Psychosocial Nursing, 34(11): 31-9.

28 PARKER, W., KISTNER, U., GELB, S., KELLY, K. \& O'DONOVAN, M. (2000) Economic Impact of HIV/AIDS in South Africa and its Implications for Governance: A Bibliographic Review. Johannesburg: CADRE \& USAID.

29 PAUKERT, F. (1973) "Income distribution at different levels of development: A survey of evidence", International Labour Review, 108: 97-125.

30 POKU, N.K. (2001) "Africa's AIDS crisis in context: 'How the poor are dying", Third World Quarterly, 22(2): 191-204. 
31 RAVALLION, M. (1992) "Poverty comparisons: A guide to concepts and methods", LSMS Working Paper, No. 88. Washington, DC: World Bank.

32 RAVALLION, M. (1994a) "Measuring social welfare with and without poverty lines", American Economic Review (Papers and Proceedings), 84(2): 359-64.

33 RAVAlliOn, M. (1994b) Poverty Comparisons, Switzerland: Harwood.

34 RAVALLION, M. (1996) "Issues in measuring and modeling poverty", Economic Journal, 106: 1328-43.

35 RAVALLION, M. \& BIDANI, B. (1994) "How robust is a poverty profile?” World Bank Economic Review, 8(1): 75-102.

36 RAVALLION, M. \& SEN, B. (1996) "When method matters: Monitoring poverty in Bangladesh", Economic Development and Cultural Change, 44: 761-92.

37 ROSEN, S. \& SIMON, J. (2002) "Shifting the burden of HIV/AIDS", Paper presented at IAEN AIDS and Economics Symposium, Barcelona, 6-7 July.

38 STATISTICS SOUTH AFRICA (2000) Measuring Poverty, Pretoria: Statistics South Africa.

39 TOPOUSZIS, D. (2000) "Measuring the impact of HIV/AIDS on the agricultural sector in Africa", Paper presented at the African Development Forum, Addis Ababa, 3-7 December.

40 UNAIDS (2002) South Africa: Epidemiological Fact Sheets, http://unaids.org (downloaded 10 September 2002).

41 UNDP (1998) "Socio-economic impact of HIV and AIDS on rural families in Uganda: An emphasis on youth", Study Paper No. 2 HIV and Development Programme, New York: UNDP.

42 WEKESA, E. (2000) "Impact of HIV/AIDS on child survival and development in Kenya", AIDS Analysis Africa, 10(4): 12-14.

43 WHITESIDE, A (2001) "AIDS and poverty: The links", AIDS Analysis Africa, 12(2): 1-5.

44 WHITESIDE, A. (2002) "Poverty and HIV/AIDS in Africa", Third World Quarterly, 23(2): 313-32.

45 WOOLARD, I. \& LEIBBRANDT, M. (1999) "Measuring poverty in South Africa", Development Policy Research Unit (DPRU) Working Paper, No. 99/33, Cape Town: University of Cape Town.

46 WOOLLEY, F.R. \& MARSHALL, J. (1994) "Measuring inequality within the household", Review of Income and Wealth, 40(4): 415-31.

47 WORLD BANK (1998) Confronting AIDS, Washington, DC: World Bank. 